\title{
A mixed-methods feasibility study of a goal-focused manualised intervention to support people with dementia to stay living independently at home with support from family carers: NIDUS (New Interventions for Independence in Dementia Study) Family
}

\author{
Abstract (247/250 words)
}

Objectives: To examine the feasibility and acceptability of NIDUS-Family, a 6month, 6-8 session manualised, individually tailored, modular intervention to support independence at home for people with dementia; and explore participants' and facilitators' experiences of the intervention.

Method: In this single group multi-site feasibility study, trained, supervised nonclinically qualified graduates (known as facilitators) delivered NIDUS-Family to family carer and people living with dementia dyads. We recruited participants from GP practices and memory services in London and Bradford. We completed quantitative outcomes intended for a full trial pre and post-intervention; and conducted qualitative interviews with participants and facilitators. Our prespecified main outcomes were: proportion of potential participants approached who agreed to participate, intervention adherence and acceptability to family carers, and facilitator fidelity to the manual.

Results: We recruited 16 dyads (57\% of those approached); 12 (75\%) completed the intervention. Of 12 participants rating intervention acceptability, $9(75 \%)$ agreed or strongly agreed that it had helped them; 2 (18\%) neither agreed nor disagreed and $1(8 \%)$ disagreed. Mean facilitator fidelity was high (81.5\%). Dyads set on average 3.9 goals; these most commonly related to: getting out and about and increasing activity/hobby participation $(n=10)$; carer wellbeing $(n=6)$, managing physical complaints $(\mathrm{n}=6)$; meal preparation/cooking $(\mathrm{n}=5)$; and reducing irritability, frustration or aggression $(n=5)$. Almost all secondary outcomes changed in a direction indicating improvement. In our qualitative analysis we identified three overarching themes; relationships facilitate change, goal-focused versus manualised approach and balancing the needs of carers and people with dementia. 
Conclusion: NIDUS-Family, delivered by non-clinically qualified facilitators, was feasible and acceptable to participants. Following refinements, testing in a pragmatic trial is underway.

Keywords: dementia; caregiver; therapeutics; feasibility studies

\section{Introduction}

Around 850,000 UK people live with dementia, two-thirds in their own homes (Prince et al., 2014). Most want to continue to do so independently (Lord et al., 2020), but care at home often breaks down. Challenging or distressing behaviours, family carer stress, poor relationships with home-care services, poor self-care and home safety risks contribute to this (Lord et al., 2016).

NIDUS-Family is a theory and evidence-based intervention, designed to meet the needs of people with dementia, and family carers who support them, so they can live as well and independently as possible at home (Lord et al., 2020). The theoretically informed model underpinning NIDUS-family described by Lord et al, stresses that care should: (1) be compassionate and centred around the person living with dementia, their important relationships and family carers. (2) Balance both the autonomy and the safety of the person living with dementia. (3) Value connections with previous roles and networks. (4) Modify the environment to be "dementia friendly". (5) Tailor activity to the individual. This can be done by (6) Identifying and prioritising the needs and goals of people living with dementia and their family carers. (7) Using strategies to reduce disabilities from behavioural and functional impairment. (8) Enabling self-management. Ultimately, this should be delivered within a service where people living with dementia and family carers have (9) a single point of contact and (10) consistent joined up care. As such, we have co-produced a relational intervention, focused upon the needs and goals of people living with dementia. It is delivered to dyads of people living with 
dementia and their family carers or, if people have symptoms that would make it difficult to meaningfully participate in intervention sessions, to family carers alone. The UK National Institute for Health and Care Excellence (NICE) recommends psychosocial and occupational therapy-based interventions to promote wellbeing and independence for all people with dementia (NICE, 2018), but few receive this in practice (Gage et al., 2015). Existing complex interventions associated with slower functional decline or living at home for longer in people with dementia have been tailored to the needs of people living with dementia (Scott et al., 2019, Lord et al., 2020) and individually delivered by health professionals (e.g. occupational therapists, physiotherapists). A community based occupational therapy intervention demonstrated improved functioning in people living with dementia and reduced carer burden, sustained after twelve weeks (Graff et al., 2006). A recent RCT of goal oriented cognitive rehabilitation for people with early stage dementia found sustained improvements in participant goals and was delivered by occupational therapists and nurses (Clare et al., 2019), similarly an ongoing RCT of self-management for people living with dementia and their spouses is delivered by occupational therapists (Sprange et al., 2015, Mountain, 2017). Delivery of manualised psychosocial interventions by non-clinically qualified staff, with training and supervision, has increased reach of evidence-based interventions in the UK and was recently trialled in a feasibility trial of an intervention for living well with dementia (Csipke et al., 2020). A 2019 London memory service audit indicated that a fifth of clients received Cognitive Stimulation Therapy (CST) (Woods et al., 2012) and a third of services reported offering the START intervention (STrAtegies for Relatives) (Livingston et al., 2019) (NHS London clinical networks, 2019). While London is relatively well-resourced, these findings are promising. To increase the chances of having a scalable and cost-effective intervention 
NIDUS-Family is delivered by non-clinically qualified staff who are potentially less expensive to employ in NHS and third sector organisations.

Multi-component interventions have demonstrated positive outcomes on a range of measures for people living with dementia and their carers, with no statistically significant difference between interventions for family carers alone versus dyadic interventions (Laver et al., 2017). Outcomes that matter most to people living with dementia and their families vary greatly between individuals, and over time. Early on, they may prioritise preserving function; as the disease progresses, goals may shift to maintaining mobility, controlling neuropsychiatric symptoms and reducing caregiver strain (Jennings et al., 2018). We used Goal Attainment Scaling (GAS) as our primary outcome, asking dyads to set goals that reflected what they considered most important in enabling them to live well and as independently as possible at home (Jennings et al., 2018).

Pragmatic interventions must be tailored to the context in which they are delivered. At time of writing, the global response to the Covid-19 epidemic is changing our lives. We are currently delivering NIDUS-Family in this challenging context, in our full Randomised Controlled Trial (RCT), which commenced March 2020, as social distancing was enforced (https://www.isrctn.com/ISRCTN11425138).

To our knowledge, NIDUS-Family is the first manualised intervention tailored to personal goals of people living with dementia and their families, and delivered by facilitators without clinical qualification. We trained and supervised facilitators to support dyads to set goals using GAS (Rockwood et al., 2003, Rockwood et al., 2002a) and to select and deliver intervention modules aligned with these goals. We report here findings from our mixed-methods non-randomised feasibility and acceptability study. Our objectives to assess feasibility and acceptability were to: (1) pilot our recruitment 
and assessment processes; (2) explore family carers, people living with dementia and facilitators experience of the intervention; (3) report intervention acceptability to family carers; and (4) facilitator fidelity to the intervention.

\section{Method}

\section{Design}

We conducted a six-month pre/post-test single group, multi-site feasibility study of NIDUS-Family; with a mixed-methods explorative design.

Nidus-Family intervention

We coproduced NIDUS-Family in a series of workshops with family carers, health practitioners and researchers, using findings from our earlier qualitative study exploring how different stakeholder groups understand independence for people living with dementia (Rapaport et al., 2020, Herat-Gunaratne et al., 2020), existing interventions (Livingston et al., 2019, Livingston, 2018, Kales, 2015, Orgeta et al., 2019) and lived experiences and expertise (Burton et al., 2019). The main premise of the intervention is for family carers and/or people with dementia to select personal goals and modules to help them achieve these goals. The intervention is delivered over 6-8 sessions, to either family carers alone or to the family carer/person with dementia dyad. The intervention was designed to address the needs of people living with dementia at all severities and subtypes, and its modular design allowed facilitators to address a broad range of personalised goals. This maximised the potential reach, applicability and inclusivity of the intervention. The primary focus of the intervention was enabling the person with dementia to live as well and independently as possible. With this purpose in mind, facilitators explored with dyads, at baseline and throughout the intervention, who it would be most helpful to deliver sessions to; often, especially for people with more severe dementia, this was the family carer alone, where the person with dementia was considered unlikely to be able to participate or if they could potentially find sessions distressing. During the first 
session, facilitators revisit goals with participants, mapping support networks, signposting to existing resources and services and planning which goal the participant would like to address first. In the intermediate sessions (this was planned as between 4-6 sessions depending on carer goals), the facilitator delivers one or occasionally two intervention components (selected from 29 possible components grouped into ten modules - see Figure 1). Five modules incorporate the DICE approach (Describe, Investigate, Create, Evaluate) to understanding and managing behaviours (Kales, 2015). At the end of each session, participants make a plan to try out strategies, the impact of which is at the next session. At the final session, the facilitator helps participants develop an action plan to use post-intervention. Intervention delivery and facilitator training and supervision

To minimise the intervention costs and therefore increase scalability NIDUS-Family was designed to be delivered by graduates in psychology or relevant social science disciplines, but without formal clinical training (therefore excluding qualified nurses, occupational therapists or practitioner psychologists). We trained three psychology graduates without clinical qualification, with experience of working with people with dementia, to deliver NIDUS-Family. Training focused on GAS, understanding dementia, clinical skills, NIDUS-Family content and mapping goals to modules. Experts by experience role-played sessions with facilitators and research team clinicians formally assessed facilitators role-playing GAS and intervention delivery.

The intervention was delivered in 6-8 sessions, over 4-6 months, at the participant's home or the facilitator's workplace. Sessions were delivered to dyads, or the family carer alone, depending on goals, the dyad's circumstances and wishes and the person with dementia's capacity to participate. Participants set goals across a range of areas which were mapped onto personalised intervention modules. All intervention sessions were recorded to assess fidelity to the intervention. 
Facilitators received weekly group supervision with a clinical psychologist troubleshooting barriers to delivery and exploring strategies for engagement. A member of the research team was available for support between supervision meetings.

\section{Sampling and participants}

We recruited family carer/person with dementia dyads over three months in 2019 from GP practices and memory services in London and Bradford. We included dyads where family carers had at least weekly contact with the person living with dementia; spoke English and had capacity to consent; who cared for people with a dementia diagnosis of any severity, living in their own home. In accordance with the Mental Capacity Act (Department of Health, 2005), people with dementia did not need capacity to consent as long as a personal consultee was identified who provided written assent; and those receiving palliative care or considered to be in the last six months of their life were excluded. We had this exclusion criteria as our follow up was at six months and we did not include a specific module on end of life care in our intervention.

\section{Ethical approval and trial registration}

London-Camden and Kings Cross National Research Ethics Committee approved the study (19/LO/0423); and we registered the protocol (ISRCTN99460116).

\section{Interviews and measures}

After obtaining written informed consent, or personal consultee declarations for people with dementia lacking capacity, researchers conducted baseline assessments. We collected all outcomes intended for a full RCT of NIDUS-Family at baseline and postintervention, for which family carer-rated GAS was the intended primary outcome.

GAS is valid, reliable and responsive to change in function in people living with 
dementia (Rockwood et al., 2002b, Rockwood et al., 2003). Researchers worked with family carers (and people with dementia who could contribute) to set SMART (Specific, Measurable, Achievable, Realistic and Timely) goals related to the person living with dementia across domains of: cognition, instrumental activities of daily life/self-care, mood, behaviour and mobility. Additionally, family carers could set goals related to their own wellbeing. Getting family carers and people living with dementia to articulate goals is recognised to be therapeutic in itself and it is acknowledged that achieving a person living with dementia's goals often relies upon support from a family carer (Jennings et al., 2018). Those setting goals may begin to make sense of their current dilemmas and understand what improvement might look like. For others, saying their fears out loud in understanding what worsening might look like offers a way to consider strategies to avoid the worse outcome. The researcher shared goals with the research team to ensure they were SMART. Where the team advised changes to goals, the researcher discussed and agreed these changes with participants. At follow-up assessment, both family carers and researchers evaluated 'performance' on baseline goals, on a 5-point scale ("much worse" to "much better" than expected).

Family carers also completed:

- The Disability Assessment for Dementia scale (DADS), a valid and reliable standard measure of functional independence (basic and instrumental activities of daily living) (Feldman et al., 2001);

- The DEMQOL proxy, to measure the person living with dementia's quality of life. The DEMQOL proxy has psychometric properties at least as good as other dementia-specific quality of life instruments (Banerjee et al., 2004).

- The Neuropsychiatric inventory (NPI), a validated instrument which assesses 12 domains of neuropsychiatric symptoms in dementia (Cummings, 1997). 
- The Client Services Receipt Inventory (CSRI) a widely used measure of service utilisation, accommodation and other cost-related variables (Beecham and Knapp, 1992).

- The Carerqol is a validated measure of care-related quality of life in informal caregivers (Brouwer et al., 2006).

- Hospital Anxiety and Depression Scale (HADS), an extensively validated measure of carer mood (Bjelland et al., 2002).

- The Modified Conflict Tactics Scale (MCTS) to measure family carer-reported potentially abusive behaviours, The measure has been extensively used among people with dementia and family carers (Cooper et al., 2008, Cooper et al., 2009, Beach et al., 2005).

We defined caseness on these measures using accepted cutpoints of $>9$ for HADSanxiety and HADS-depression scores (Bjelland et al., 2002), and >1 for MCTS (Beach et al., 2005).

People with dementia were asked to complete the DEMQOL to measure their quality of life (Banerjee et al., 2004), if able.

Post-intervention we asked family carers and people with dementia who had participated in intervention sessions complete an acceptability questionnaire to rate their agreement with the statement that the intervention had helped them on a 5-point Likert scale (one-strongly disagreed to five-strongly agreed). The questionnaire also invited written feedback on the intervention (See appendix 1 for acceptability questionnaire). Semi-structured qualitative interviews were conducted with a purposive sample of dyads exploring their experiences of the intervention and facilitators were interviewed about interview delivery (See appendix 2 for topic guides). We selected the sample of dyads to ensure we had participants from each research site, who had received the 
intervention from each facilitator and to represent both spousal and child carers for those with varying dementia severity. Qualitative interviews were conducted by researchers who had not collected outcomes or delivered the intervention to interviewees. We ceased interviews after reaching thematic saturation, the point at which no further themes emerged from discussions and reflections on additional interviews (Guest et al., 2016).

\section{Analysis}

\section{Quantitative}

We reported the proportion of eligible people approached who took part and completed assessments; and the number of intervention sessions received. We summarised participants' demographic characteristics; and scores on pre and post-intervention assessments, including change in score with $95 \%$ confidence intervals. We report normalised GAS scores. As people had different numbers of goals, a summary formula is required to standardise the degree of goal attainment:

$$
T=50+\frac{10 \Sigma x_{i}}{\sqrt{0.7 n+0.3 n^{2}}}
$$

where $x_{i}$ is the degree to which the goal is achieved [-2 = much worse, $+2=$ much better] and $n$ is the number of goals $i=1, \ldots, n[26]$. The score can be interpreted as follows: $\mathrm{T}=50=$ met baseline expectations (no change) $\mathrm{T}<50=$ did not meet expectations (worsened); $\mathrm{T}>50=$ exceeded expectations (improved).

\section{Qualitative}

We used NVivo12 software to organise data, taking an inductive thematic analytic approach (Braun and Clarke, 2006). To increase reliability co-authors systematically 
double-coded all interviews with facilitators $(n=3)$, participants $(n=5)$ and written responses from acceptability questionnaires completed by participants $(n=12)($ Barbour, 2001). Researchers read transcripts for accuracy, anonymity and to familiarise themselves with the data, then labelled meaningful fragments of text with initial codes. After a subsample of each dataset had been inductively coded we met as a research team and discussed our initial codes. Discrepancies were discussed between researchers until we reached consensus. As a team we developed an initial coding frame addressing the key research objectives. The first author then revisited all the data to integrate data into the coding frame consulting with the wider research team throughout to agree the final thematic analysis presented here.

\section{Fidelity of intervention delivery}

We designed fidelity checklists for each session based upon our work testing other interventions (Livingston, 2018, Livingston et al., 2019). These comprised a list of the components of each session and three process measures described below (See appendix 3 for sample fidelity checklist). We applied fidelity checklists to $20 \%$ of audio recorded intervention sessions randomly, calculating the proportion of expected checklist items identified as delivered; and reporting the mean proportion across assessed sessions. Three senior members of the research team listened to the audio recordings and rated the checklists. We adopted established thresholds to rate fidelity (Noell, 2002): 81$100 \%$ constituted high fidelity, 51-80 moderate and $<50 \%$ low fidelity. We rated the process measures on a 5-point scale (1- not at all to 5- very much) whether the facilitator kept: to time, the carer focused on the manual and goals, and participant(s) engaged. 


\section{Results}

\section{Sample}

35 out of 101 dyads approached (34.7\%) to participate via mail out or a face to face request, agreed to be contacted. We had a better response from face to face approach by clinicians (32 approached, 27 agreed to be contacted and 11 consented) than from mail out to potential participants (69 approached, 8 agreed to be contacted and 5 consented). Of the 35 eligible dyads we recruited $16(45.7 \%)$ from two GP practices and two memory services in London and Bradford. 14 participant dyads received the intervention; of those not receiving the intervention, one was uncontactable after initial meeting and one could not formulate goals. 11/14 (79\%) dyads who received the intervention completed the post-intervention outcomes. For 1 dyad, the person with dementia died after intervention but before follow-up, so we did not complete follow-up outcomes but the carer rated intervention acceptability. Two dyads withdrew before completing the intervention or post-intervention outcomes. The flow of participants through the study is reported in Figure 2. Baseline demographic characteristics are reported in Tables 1 and 2 .

\section{Intervention acceptability and fidelity}

$12 / 14(86 \%)$ of dyads who commenced the intervention, received the planned 6-8 session intervention; 10 received eight, one received seven and one received six sessions. Two participants withdrew after receiving two and three sessions respectively (one carer fractured their hip and felt unable to continue, the other reported not having time). All intervention sessions were delivered to a family carer; for seven dyads, the person living with dementia never attended, four dyads attended all sessions, and three dyads attended some sessions. In one dyad, additional family members joined some 
session and in another a paid carer joined. When people with dementia did not join intervention sessions this was primarily because it was felt by them (where they had capacity to make this decision) and their family carer that they would struggle to participate or become distressed by the discussion. These conversations were discussed by facilitators in their clinical supervision.

Twelve acceptability questionnaires were completed by; 10 family carers, one person with dementia and one dyad; $6(50 \%)$ strongly agreed that the intervention helped them; 3 (25\%) agreed; $2(17 \%)$ neither agreed nor disagreed and $1(8 \%)$ disagreed. All but three modules were delivered to some participants. Figure 1 illustrates the frequency with which module components were delivered.

Based on the 20 sessions assessed for fidelity, the mean fidelity score was $81.5 \%$ (range 57.1-100\%) indicating a high level of fidelity. The proportion of sessions rated by assessors as 4 or 5 on our 5 point scale (from 1- not at all to 5- very much met) were: keeping to time 10/20 (50\%); staying focused 11/20 (55\%); and keeping engaged 19/20 $(95 \%)$

\section{Outcomes (Table 3)}

Participating dyads set a mean of $3.9(\mathrm{SD}=0.8)$ goals (Figure 3 shows goal areas). Postintervention mean score (59.0 (95\% confidence interval 49.5 to 68.5$))$ on carer-rated GAS was in the direction of exceeding baseline expectations $(50=$ met baseline expectations). Changes on secondary continuous outcomes indicated improvement following intervention (except for anxiety caseness, which increased, though mean anxiety scores decreased).

\section{Thematic analysis}

We interviewed three family carers alone and two dyads, had twelve completed 
acceptability questionnaires ${ }^{1}$ and interviewed all three facilitators who delivered NIDUS-Family, two of whom also set baseline goals. We identified three themes: 1 . Relationships facilitate change, 2. Goal-focused versus manualised approach, 3 . Balancing the needs of carers and people with dementia. These themes and the source of the data represented within themes and subthemes are presented in Table 4.

1. Relationships facilitate change

1.1. Building rapport and trust. From both facilitator and participant perspectives, developing a trusting and open relationship was integral to delivering and receiving NIDUS-Family. Participants often referred to facilitator's past-experience with people living with dementia increasing trust and confidence in their ability and commitment.

From the first five minutes of conversation, I really felt comfortable, and the way they presented themselves, and the fact that they talked about... You could see from them how much this intervention meant to them individually, because of their experience. (Daughter 3)

1.2. Having someone to guide you through. Family carers valued protected time to reflect upon their situation. The process of guiding (or being guided) through the intervention was perceived as integral to change.

Just having time to really think about it. That you wouldn't normally do... [The facilitator] really helped me focus and they drew out a lot of thought processes and a lot of things that I didn't really know... (Daughter 4)

\footnotetext{
${ }^{1}$ Quotations denoted by * are from the acceptability questionnaires, all other quotations are from interviews.
} 
This guided exploration motivated family carers to take action and they felt less alone, especially when presented with examples from other carers and people with dementia in the manual.

It's very good to see the input that other people... The feedback that you've got from other people... And it makes you think, well, I did think about that, maybe we could try that. Use that, or tailor it to us, tweak it somehow. (Daughter 2)

1.3 Widening support networks. Although the intervention was primarily delivered to the dyad, or the family carer alone, in two cases others contributed and the intervention focused on wider relationships and informal support networks as well as professional services and local resources.

[It] was really helpful, because it wasn't just focused on us. It was the wider family and how we can all chip and help to change things. (Daughter 1)

Family carers and facilitators described how the intervention served to widen available support networks, reducing feelings of guilt or worry about asking for and accepting support:

I have learned to accept help and to seek help. (Daughter 5*)

I've kicked off with people as well, which I probably wouldn't have done. Insisted that the doctors are more on the ball and that type of thing. (Daughter 5)

1.4 Improved relationships and understanding. Family carers spoke about developing better understanding of their relatives' needs, particularly when their relative was unable to communicate directly, helping them, in turn to adapt their responses.

Communication was the main thing that helped. Understanding that dementia was 
difficult and frustrating. Dad couldn't tell me what he needed. I got better at looking out for signs. (Son $1 *)$

2. Goal-focused versus manualised approach

2.1 Personalised goal setting is difficult but worth it. Central to the personalised nature of the intervention was the initial structured goal setting. Many participants and all facilitators described this as challenging but in itself therapeutic.

It did feel quite challenging setting the goals, to begin with. But then, as it went on, it felt like we had... Because I guess I didn't realise, because everything just felt fuddled and clouded and oh my God, what do I do? (Daughter 5)

Participants and facilitators felt that individually tailored goals were intrinsic to the success of the intervention.

It was just literally having the time to sit and think about what I'm doing and being able to decide on two or three goals... Whereas, I think, without the study, it's all just an overwhelming day, day after day, and you don't, I don't ever really think about how we can improve one aspect. (Daughter 2)

Facilitators perceived challenges when goals set at baseline were no longer relevant or did not fit with the intervention. Sometimes this was because circumstances changed, for example if the person living with dementia became unwell. At other times, as dyads progressed through the intervention, their perspective on 'meaningful change' shifted; and diverged from set goals.

When the intervention starts, I think there are other things that people realise actually this is something I should've set as a goal, but now it's too late because we've done that already. I didn't want to just leave them with this problem, so I tried to fit in the module 
that was relevant to this problem that they had, but it wasn't an identified goal. (Facilitator 3)

Facilitators discussed the dual function of goals as primary research outcomes and as a framework for the intervention. Embedding goals was perceived as a key strength, yet the inflexibility in changing goals during the intervention could be limiting.

I think that can be disheartening sometimes, not just for them for you a bit...Yes, repeating every week, and in the case where they don't want to work towards those goals anymore, yet you're still bringing them back to it every time. (Facilitator 2)

2.2 Sticking to the manual isn't always easy. Facilitators found it challenging to know when to stick to the manualised intervention content and when to take a more personalised approach; giving participants more time to talk or answering questions raised. Facilitators sometimes felt less confident when conversations moved away from structured content.

At certain points I felt like I didn't know what to say, and it was maybe my own fault for coming away from the manual and feeling like I had to give an answer if I couldn't find it in the book. (Facilitator 3)

Participants highlighted times when they felt that manualised content did not fit with their experiences. Often they related this to the person with dementia having mild symptoms and the examples in the manual focusing more on those with a higher level of need. Some participants talked about not being 'typical' of those being targeted by the intervention or of having less 'need'.

I think it would be a wonderful thing for somebody who is more, with real dementia and 
the couple and for the partner...Just think it would be excellent for somebody who's got nothing else to do. (Wife 1)

When faced with this perceived lack of fit, facilitators would flexibly adapt delivery by either missing parts of the content, adapting examples or suggesting that some of the information may feel more useful in the future.

Ifeel like they can feel a bit stuck in the pattern of saying, this isn't relevant now, and me reiterating, maybe not now but let's focus on the bits that do apply, or let's think about the future. It can just be quite tricky. (Facilitator 2)

\section{Balancing the needs of carers and people living with dementia}

NIDUS-Family was designed to be delivered to dyads where possible, focusing on both of their needs in developing goals centred on the person with dementia living well at home, whilst acknowledging that their perspectives hopes and wishes may not always align. Facilitators navigated a path between the needs of the carer and the person with dementia; developing goals to benefit both.

There were loads of times where the carer would suggest a goal area, say getting out and about more, and the person with dementia would say, I'm already doing this much, even if that's not the case. And that's really difficult to handle in the room sometimes, because it's a disagreement over the specifics, which is something you're really focusing on when you're doing GAS. (Facilitator 2)

3.1 When and how to include the person living with dementia? Ensuring that the content was understandable for the person living with dementia and that being present (or absent) did not inadvertently leave them feeling excluded or confused, could be 
challenging. People with dementia described finding aspects of the intervention, and the manual, confusing and difficult to follow.

Because it was a discussion... She said, oh, well, you do this, or you do that, and then I could do it. But when there was nobody there, I just looked at it and I thought, what? (Female person living with dementia 1)

Facilitators were aware that some people living with dementia were confused by the written manuals, working hard within the sessions to manage this.

But the other person living with dementia [did have the manual] and that's actually been really helpful. The first couple of sessions I didn't do that. I was just including her in the chat when we had the discussion, and she thought, wait, what am I doing here? I also need to have a copy of this. (Facilitator 1)

Often including the person with dementia in the sessions had a positive impact, with some family carers feeling that the process of inclusion itself facilitated independence.

When the sessions started, we were more focused on trying to see how we could help her, and what the session has done is give us the information, the insight to help her help herself... after work one day and I was a little bit late, and when I got here and asked her how she's doing, she said oh, she's fine, they've just finished eating. She managed to get herself some leftovers and heat it up in the microwave, so she was able to do that, so that was good.

Person with dementia: $\quad$ They didn't have to do it. (Person living with dementia 2 and daughter 2) 
3.2 Trying not to overlook the carer's needs. Sometimes facilitators felt it was important for family carers to have time in sessions alone, where they could talk more openly about difficulties and focus on goals related to their own wellbeing.

There are some dyads where we started out all together, and then as we progress, I just met with a carer and it really changed how the sessions felt. It felt a lot more productive, because it was easier for them to be open about it. (Facilitator 2)

When they did set a goal related to their own wellbeing, carers described feeling less stressed and more accepting of their situation.

I am less stressed and feel that there is life after diagnosis (Wife $2 *$ )

I no longer feel that I am just existing (Daughter $5 *$ )

\section{Discussion}

To our knowledge this is the first manualised intervention tailored to personalised goals of people living with dementia and their families, delivered by facilitators without clinical training. Our intervention was feasible and acceptable to family carer participants. Intervention fidelity was high and three quarters of family carers completing the intervention felt it had helped them. This is the first study to use GAS as both an outcome measure and to directly inform a non-pharmacological intervention for people living with dementia and their families, and to train non-clinical staff to set goals. Although our trial was single-arm and not powered to report efficacy, carer-rated GAS scores indicated goal expectations had been exceeded post-intervention and almost all secondary outcomes also changed in a direction indicating improvement.

Our qualitative findings have guided our adaptation of the intervention for delivery in the full RCT. We identified three overarching themes; relationships facilitate change, 
goal-focused versus manualised approach and balancing the needs of carers and people living with dementia. NIDUS-Family acknowledges tensions between independence for people living with dementia as an expression of autonomy (Manthorpe et al., 2010, Smebye et al., 2015) and interdependence that enables people with dementia to remain in their own homes and communities (Woods, 1999, Rapaport et al., 2020), with relationships intrinsic to our approach. Our qualitative findings highlight how building connections and improving communication between people living with dementia, wider family and professional networks facilitated goal directed change and was an important outcome in itself. The process was not always straight forward, with facilitators required to navigate between the needs and priorities of people with dementia and family carers. The majority of intervention sessions were delivered to family carers alone, reflecting the inclusion in the study of people living with dementia at all levels of severity. Flexibility was key in deciding when and how best to include the person with dementia; however facilitators often faced a dilemma in how flexible to be.

Our approach aligns with existing evidence that only interventions tailored to the needs of both people living with dementia and family carers increase time living at home (Lord et al., 2020). While having a manualised intervention is important for future implementation in complex real-world settings such as the NHS, having an intervention which is compatible with a personalised goal focused approach is also important. The breadth of goals chosen captured the varied priorities of the participant dyads (Jennings et al., 2018) and with support from the wider team the facilitators were able to negotiate the complexities that arose from this process.

\section{How we have learnt from these findings to inform our full RCT}

We have significantly reduced the length of each module for the main trial (through 
reducing components that in practice were experienced as repetitive), and been explicit about examples and areas facilitators may decide to omit, in discussion with supervisors, for people with milder dementia. We have refined training and support for facilitators around goal setting. We began the main trial just after we entered lockdown due to the Covid-19 pandemic. The modular and flexible nature of the intervention facilitated the necessary shift to delivery by video call or telephone. Many resources and strategies that may have been central to participants preferred goals, such as engaging and connecting outside of the house or accessing additional support, changed or became unavailable; we addressed this in our materials and our approach. For example, we developed an additional brief facilitator guide with additional information or questions that may need to be covered in response to Covid-19 and highlighted where they may wish to amend the wording of the manual to ensure that it still felt relevant during this period. The facilitators have received extra training on the impact of Covid-19 and it is revisited in their regular clinical supervision. Additionally, we are more reliant on family carers to facilitate online or telephone contact with people living with dementia as part of the intervention. We have been able to recruit, consent and deliver the intervention to family carers and people living with dementia remotely and will report on the acceptability and any limitations of this approach in our process evaluation of the main RCT. We do not know how long restrictions will be in place and the social impact of the pandemic will undoubtedly be long lasting. Our feasibility study has enabled us to test a flexible intervention which will ultimately, if clinically and cost effective, result in more diverse models of implementation being available.

\section{Strengths and limitations}

We recruited in London and Bradford across primary and secondary care settings, 
reflecting the populations we will target in our full trial. Although Bradford extends into more rural areas these are primarily urban or semi-urban and we will be recruiting more broadly in our full RCT. As this was a feasibility study, we were broad in our inclusion criteria. One dyad left the study because they were unable to set goals (they could not identify enough areas in which they wanted things to change). We have added an exclusion criteria to our main trial for people who are unable to identify three areas in which they want to set goals at baseline. We now emphasise in training and supervision that goals set should facilitate rather than impede intervention delivery - and that ultimately carers' current priorities should determine intervention content, in situations where they no longer want to work on a goal set at baseline. As noted in Figure 1, not all intervention modules were tested and some were used only once. We have retained these modules for the full trial and revised them based on the general feedback received during this feasibility study.

We selected our study design - a non-randomised feasibility study - based on our study aim, which was to test the feasibility and acceptability of the NIDUS family intervention, and how we linked it to GAS. While a randomised design would have been more appropriate if we had been evaluating recruitment rate, we have previously demonstrated successful recruitment in similar trials (Livingston, 2018, Livingston et al., 2013) so this was not the purpose of this study.

This evaluation was conducted by the research team who developed and tested the intervention. Further, we were unable to qualitatively interview participants who did not complete the intervention, though we did informally talk to the two participants who dropped out and their feedback aligned with that presented here. They particularly highlighted the demands upon their time and the need to simplify and reduce the paperwork associated with the intervention. In our full RCT we will be conducting an 
external process evaluation and will seek to interview participants who did not complete the intervention, mitigating these potential sources of bias.

\section{Conclusions}

NIDUS-Family was feasible and acceptable. We achieved high fidelity and adherence to the intervention suggesting that we can successfully train non-clinical staff to deliver it, an important dimension to potential future scalability. We were able to set meaningful and personalised goals and integrate these into the intervention. This has positioned us well for our full RCT currently running and incorporating Covid-19 mitigation. That our outcomes changed after the intervention in a direction indicating improvement bodes well for our ongoing RCT. 
Table 1. Baseline characteristics of family carers

\begin{tabular}{|l|l|}
\hline Results are $n(\%)$ unless specified otherwise & Total $\left(\mathbf{n}=\mathbf{1 5}^{*}\right)$ \\
\hline Age (years), mean (SD), $\mathrm{n}=13$ & $61.3(14.1)$ \\
\hline Gender & \\
Males & $5(33)$ \\
Females & $10(67)$ \\
\hline Ethnicity & $2(13)$ \\
Black & $13(87)$ \\
White & \\
\hline Highest education achievement & $6(40)$ \\
Degree or equivalent & $1(7)$ \\
Higher Education & $1(7)$ \\
A Level or equivalent & $3(20)$ \\
GCSEs & $3(20)$ \\
Other Qualifications & $1(7)$ \\
No formal qualification & $11(73)$ \\
\hline Marital status & $2(13)$ \\
Married & $2(13)$ \\
Divorced & \\
Single & $6(40)$ \\
\hline Relationship of carer & $7(47)$ \\
Spouse & $1(7)$ \\
Child & $1(7)$ \\
Friend & $13(87)$ \\
Nephew & $2(13)$ \\
\hline First language & $9(60)$ \\
English & $2(13)$ \\
Other (Portuguese, Yourba/Fanti) & $2(13)$ \\
\hline Living situation, & $2(13)$ \\
Lives with partner/spouse & $11(73)$ \\
Lives alone & $4(27)$ \\
Lives with parent(s) & \\
Other (partners and parents / partner and children) & \\
\hline Accommodation type & \\
Owner occupied & \\
Council rented & \\
\hline & \\
\hline
\end{tabular}

$n=$ total number of participants with data available; $\mathrm{SD}=$ standard deviation; *One participant did not provide any baseline characteristics for the carer. 
Table 2. Baseline characteristics of people living with dementia

\begin{tabular}{|c|c|}
\hline Results are $n(\%)$ unless specified otherwise & Total $\left(n=15^{*}\right)$ \\
\hline Age (years), mean (SD) & $84.3(14.2)$ \\
\hline $\begin{array}{l}\text { Gender } \\
\text { Males } \\
\text { Female }\end{array}$ & $\begin{array}{l}7(47) \\
8(53)\end{array}$ \\
\hline $\begin{array}{l}\text { Ethnicity } \\
\text { Black } \\
\text { White } \\
\text { Other }\end{array}$ & $\begin{array}{l}2(13) \\
12(80) \\
1(7)\end{array}$ \\
\hline $\begin{array}{l}\text { Highest education achievement } \\
\text { Degree or equivalent } \\
\text { Higher Education } \\
\text { GCSEs } \\
\text { No formal qualification }\end{array}$ & $\begin{array}{l}5(33) \\
1(7) \\
2(13) \\
7(47)\end{array}$ \\
\hline $\begin{array}{l}\text { Marital status } \\
\text { Married } \\
\text { Divorced } \\
\text { Single } \\
\text { Widowed } \\
\end{array}$ & $\begin{array}{l}6(40) \\
2(13) \\
1(7) \\
6(40)\end{array}$ \\
\hline $\begin{array}{l}\text { First language } \\
\text { English } \\
\text { Other (Italian, Spanish, Arabic) }\end{array}$ & $\begin{array}{l}12(80) \\
3(20)\end{array}$ \\
\hline $\begin{array}{l}\text { Dementia diagnoses } \\
\text { Alzheimer's } \\
\text { Lewy body dementia } \\
\text { Vascular } \\
\text { Mixed - Alzheimer's and Vascular } \\
\text { Unable to specify }\end{array}$ & $\begin{array}{l}5(33) \\
1(7) \\
2(13) \\
3(20) \\
4(27)\end{array}$ \\
\hline Time since diagnosis years (mean, SD) , $n=10$ & $3.0(3.1)$ \\
\hline $\begin{array}{l}\text { Living situation } \\
\text { Lives with partner/spouse } \\
\text { Lives alone } \\
\text { Lives with children } \\
\text { Other (partner and children) }\end{array}$ & $\begin{array}{l}5(33) \\
5(33) \\
4(27) \\
1(7)\end{array}$ \\
\hline $\begin{array}{l}\text { Accommodation type } \\
\text { Owner occupied } \\
\text { Private rented } \\
\text { Council rented }\end{array}$ & $\begin{array}{l}10(67) \\
1(7) \\
4(27)\end{array}$ \\
\hline
\end{tabular}


Table 3. Outcome measures, pre (baseline) and post-intervention

\begin{tabular}{|c|c|c|c|c|c|c|}
\hline $\begin{array}{l}\text { Values are mean (SD) unless } \\
\text { specified otherwise (Score } \\
\text { range) }\end{array}$ & $n$ & $\begin{array}{l}\text { Pre- } \\
\text { intervention } \\
(\mathrm{N}=16)\end{array}$ & $n$ & $\begin{array}{l}\text { Post- } \\
\text { intervention } \\
(\mathrm{N}=11)\end{array}$ & $n$ & $\begin{array}{l}\text { Mean/Difference* } \\
\text { (pre-post) }(95 \% \\
\text { confidence } \\
\text { interval) }\end{array}$ \\
\hline $\begin{array}{l}\text { Primary outcome } \\
\text { Goal Attainment Scaling } \\
\text { (carer-rated) }\end{array}$ & 1 & - & 11 & $59.0(14.1)$ & 11 & $59.0(49.5,68.5)$ \\
\hline $\begin{array}{l}\text { Secondary outcomes } \\
\text { Goal Attainment Scaling } \\
\text { (researcher-rated) } \\
\text { DAD }(0-\underline{100})\end{array}$ & 1 & $\begin{array}{l}- \\
56.8(32.9)\end{array}$ & 10 & $\begin{array}{l}59.9(14.2) \\
60.9(31.7)\end{array}$ & 10 & $\begin{array}{l}59.9(50.3,69.4) \\
3.58(-9.60,16.8)\end{array}$ \\
\hline $\begin{array}{l}\text { DEMQOL }(28-\underline{112}) \\
\text { DEMQOL proxy total }(31-\underline{124})\end{array}$ & $\begin{array}{l}9 \\
1\end{array}$ & $\begin{array}{l}78.4(13.6) \\
88.3(18.9)\end{array}$ & $\begin{array}{l}4 \\
10\end{array}$ & $\begin{array}{l}84.3(8.5) \\
99.6(11.9)\end{array}$ & $\begin{array}{l}4 \\
10\end{array}$ & $\begin{array}{l}-6.00(-23.8,11.8) \\
-6.19(-15.4,2.98)\end{array}$ \\
\hline $\begin{array}{l}\text { Neuropsychiatric inventory } \\
\text { Severity total }\end{array}$ & 1 & $6.50(4.43)$ & 11 & $4.55(2.34)$ & 11 & $0.36(-1.87,2.60)$ \\
\hline Frequency total & 1 & $12.7(9.0)$ & 11 & $7.4(3.6)$ & 11 & $2.64(-3.12,8.39)$ \\
\hline Total score ( $\underline{0}$ to 144$)$ & 1 & $20.0(17.0)$ & 11 & $9.36(4.50)$ & 11 & $4.82(-4.88,14.5)$ \\
\hline CarerQol (0-100) & 1 & $74.4(17.6)$ & 11 & $77.8(9.4)$ & 11 & $-3.85(-15.3,7.59)$ \\
\hline $\begin{array}{l}\text { CarerQol VAS }(0-\underline{10}) \\
\text { HADS }\end{array}$ & 1 & $6.27(2.60)$ & 11 & $6.55(1.92)$ & 11 & $0.00(-1.44,1.44)$ \\
\hline Anxiety (0-21) & 1 & $8.13(5.59)$ & 11 & $7.55(4.03)$ & 11 & $1.36(-1.36,4.09)$ \\
\hline Depression $(\underline{0}-21)$ & 1 & $5.13(5.19)$ & 11 & $3.55(2.77)$ & 11 & $1.27(-0.51,3.05)$ \\
\hline Anxiety Case, (>9) $n(\%)$ & 1 & $5(33)$ & 11 & $5(45)$ & 11 & $-0.10(-0.35,0.17)^{\mathrm{a}}$ \\
\hline $\begin{array}{l}\text { Depression Case, (>9) } n(\%) \\
\text { MCTS }\end{array}$ & 1 & $4(27)$ & 11 & $2(18)$ & 11 & $0.10(-0.17,0.35)^{\mathrm{a}}$ \\
\hline Total score $(\underline{0}-40)$ & 1 & $1.27(1.87)$ & 11 & $1.00(2.41)$ & 11 & $0.18(-1.05,1.41)$ \\
\hline Caseness, $(>2) n(\%)$ & 1 & $3(20)$ & 11 & $2(18)$ & 11 & $0.00(-0.34,0.34)^{\mathrm{a}}$ \\
\hline
\end{tabular}

*"Difference" for all continuous outcomes refers to a difference in means. For binary outcomes (marked with ${ }^{a}$ ) this refers to a difference in proportions. The positive maximum scale score is underlined. 
Table 4: Table of themes and sources of qualitative date.

\begin{tabular}{|c|c|c|c|c|}
\hline \multirow{2}{*}{$\begin{array}{l}\text { Overarching } \\
\text { theme }\end{array}$} & \multirow[t]{2}{*}{ Subtheme } & \multicolumn{3}{|l|}{ Data source } \\
\hline & & $\begin{array}{l}\text { Family carer } \\
\text { interview }\end{array}$ & $\begin{array}{l}\text { Facilitator } \\
\text { interview }\end{array}$ & $\begin{array}{l}\text { Acceptability } \\
\text { questionnaire }\end{array}$ \\
\hline \multirow{4}{*}{$\begin{array}{l}\text { 1. Relationships } \\
\text { facilitate } \\
\text { change }\end{array}$} & $\begin{array}{l}\text { 1.1 Building rapport and } \\
\text { trust }\end{array}$ & $\mathrm{x}$ & $\mathrm{x}$ & $\mathrm{x}$ \\
\hline & $\begin{array}{l}\text { 1.2 Having someone to } \\
\text { guide you through }\end{array}$ & $\mathrm{x}$ & $\mathrm{x}$ & $\mathrm{x}$ \\
\hline & $\begin{array}{l}\text { 1.3 Widening support } \\
\text { networks }\end{array}$ & $\mathrm{x}$ & $\mathrm{x}$ & $\mathrm{x}$ \\
\hline & $\begin{array}{l}\text { 1.4 Improved } \\
\text { relationships and } \\
\text { understanding }\end{array}$ & $\mathrm{x}$ & & $\mathrm{x}$ \\
\hline \multirow[t]{2}{*}{$\begin{array}{l}\text { 2. Goal focussed } \\
\text { versus } \\
\text { manualised } \\
\text { approach }\end{array}$} & $\begin{array}{l}\text { 2.1 Personalised goal } \\
\text { setting is difficult but } \\
\text { worth it }\end{array}$ & $\mathrm{x}$ & $\mathrm{x}$ & $\mathrm{x}$ \\
\hline & $\begin{array}{l}\text { 2.2 Sticking to the } \\
\text { manual is not always } \\
\text { easy }\end{array}$ & $\mathrm{x}$ & $\mathrm{x}$ & $\mathrm{x}$ \\
\hline \multirow{2}{*}{$\begin{array}{l}\text { 3. Balancing the } \\
\text { needs of } \\
\text { carers and } \\
\text { people living } \\
\text { with dementia }\end{array}$} & $\begin{array}{l}\text { 3.1 When and how to } \\
\text { include the person } \\
\text { living with dementia? }\end{array}$ & $\mathrm{x}$ & $\mathrm{x}$ & $\mathrm{x}$ \\
\hline & $\begin{array}{l}\text { 3.2 Trying not to } \\
\text { overlook the carer's } \\
\text { needs }\end{array}$ & $\mathrm{x}$ & & $\mathrm{x}$ \\
\hline
\end{tabular}


Figure 1. NIDUS-Family modules (and component sessions) and the number of participant dyads receiving them

\begin{tabular}{|c|c|c|}
\hline Module & Module component & $\begin{array}{l}n \text { dyads receiving module } \\
(\mathrm{N}=14)\end{array}$ \\
\hline \multirow[t]{2}{*}{ 1: Accepting care } & Making Decisions & 7 \\
\hline & Finances & 0 \\
\hline \multirow[t]{2}{*}{ 2: Communication } & With the person living with dementia & 7 \\
\hline & With other family and professionals & 0 \\
\hline \multirow{3}{*}{$\begin{array}{l}\text { 3: Behaviour \& } \\
\text { Emotions }\end{array}$} & Part 1 & 3 \\
\hline & Part 2 & 2 \\
\hline & Part 3 & 0 \\
\hline 4: Physical Health & & 2 \\
\hline \multirow[t]{2}{*}{ 5: Physical activity } & Physical Activity & 3 \\
\hline & $*$ Getting out and about & 6 \\
\hline \multirow{3}{*}{$\begin{array}{l}\text { 6: Behavioural } \\
\text { activation and } \\
\text { managing mood }\end{array}$} & Emotions & 4 \\
\hline & Staying Active Part 1 & 6 \\
\hline & Staying Active Part 2 & 6 \\
\hline \multirow[t]{2}{*}{ 7: Carer Wellbeing } & Part 1 & 5 \\
\hline & Part 2 & 5 \\
\hline \multirow[t]{5}{*}{ 8: Living well } & Living well at home: Part 1 & 7 \\
\hline & Living well at home: Part 2 & 7 \\
\hline & Personal Care: Part 1 & 1 \\
\hline & Personal Care: Part 2 & 1 \\
\hline & Driving & 1 \\
\hline 9: Relaxation & $\begin{array}{l}4 \text { booklets covering different } \\
\text { relaxation exercises }\end{array}$ & 4 \\
\hline \multirow[t]{6}{*}{ 10: Healthy routines } & $*$ Diet \& Healthy Eating & 1 \\
\hline & Difficulties eating \& drinking Part 1 & 1 \\
\hline & Difficulties eating \& drinking Part 2 & 1 \\
\hline & *Healthy Sleep & 3 \\
\hline & Sleep Difficulties Part 1 & 2 \\
\hline & Sleep Difficulties Part 2 & 2 \\
\hline
\end{tabular}

*Due to substantial content overlap, these components were removed for the full NIDUS-Family trial, with content amalgamated into other modules. 
Figure 2. Flow chart for the NIDUS-Family feasibility study

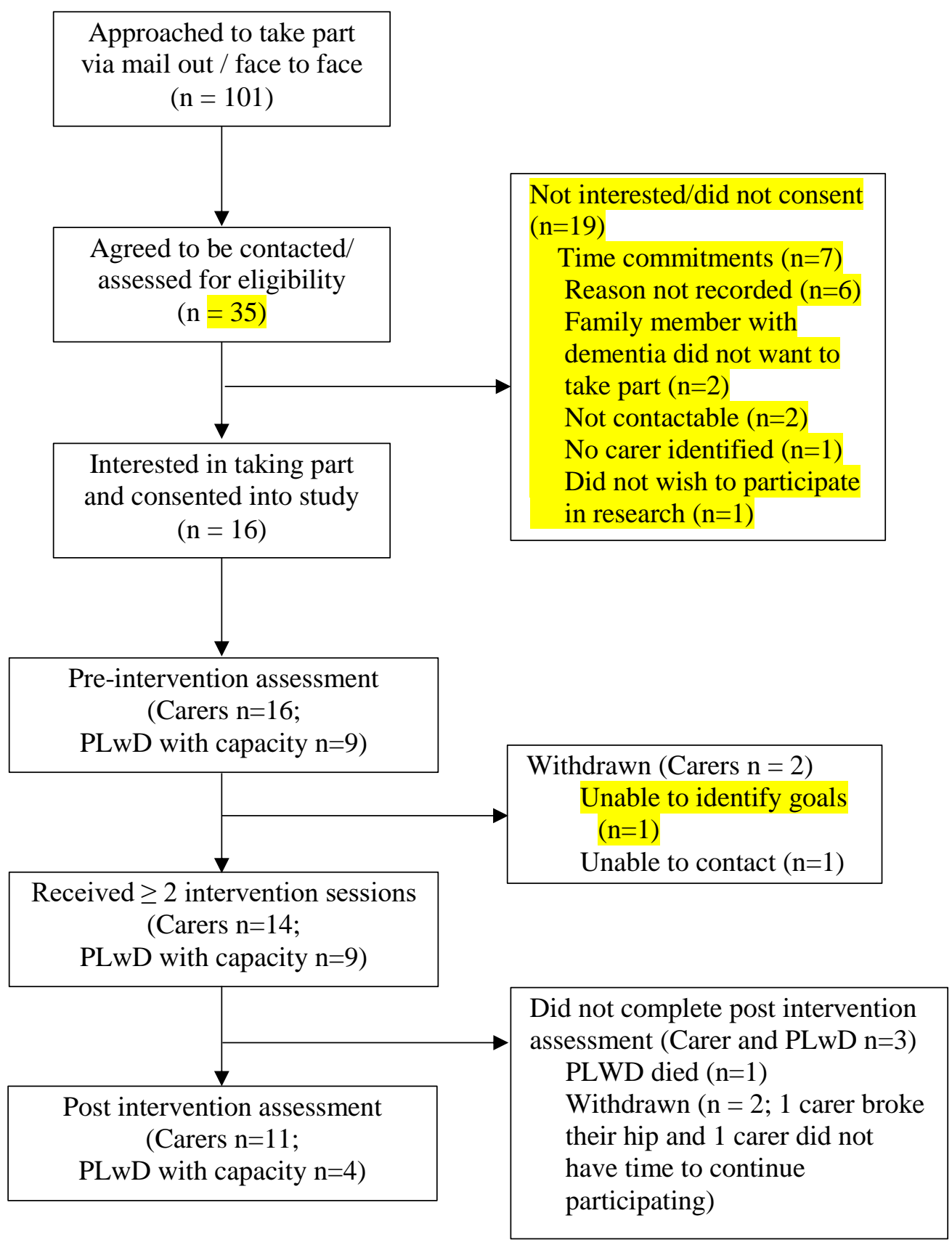


Figure 3. Goal areas selected by participants

\begin{tabular}{|l|l|}
\hline Goal area & $\boldsymbol{n}$ goals selected \\
\hline Getting out and about/increasing activity \& hobbies & 10 \\
\hline carer wellbeing & 6 \\
\hline managing physical complaints & 6 \\
\hline meal preparation/cooking & 5 \\
\hline reducing irritability, frustration or aggression & 5 \\
\hline Sleep disturbance & 4 \\
\hline managing mood or anxiety & 3 \\
\hline reducing repetitive behaviours or questioning & 3 \\
\hline Interacting with others & 2 \\
\hline Unsafe actions & 2 \\
\hline Financial management & 2 \\
\hline Interest and initiative & 2 \\
\hline Appetite & 2 \\
\hline Preparing for the future & 2 \\
\hline Disorientation to place & 1 \\
\hline Accepting additional support & 1 \\
\hline Eating independently & 1 \\
\hline
\end{tabular}




\section{References}

BANERJEE, S., SMITH, S., LAMPING, D., FOLEY, B., SMITH, P. \& MURRAY, J. 2004. DEMQOL - Evaluation of a new system for measuring quality of life in people with dementia: Validity, reliability and use in regular practice. Neurobiology of Aging, 25, S321-S321.

BARBOUR, R. S. 2001. Checklists for improving rigour in qualitative research: a case of the tail wagging the $\operatorname{dog}$ ? BMJ, 322, 1115-7.

BEACH, S., SCHULZ, R., WILLIAMSON, G., MILLER, L., WEINER, M. \& LANCE, C. 2005. Risk Factors for Potentially Harmful Informal Caregiver Behavior. Journal of the American Geriatrics Society, 53, 255-261.

BEECHAM, J. \& KNAPP, M. 1992. Costing psychiatric intervention. In: THORNICROST, C., BREWIN, C. \& WING, J. (eds.) Measuring mental health needs. London: Gaskell.

BJELLAND, I., DAHL, A. A., HAUG, T. T. \& NECKELMANN, D. 2002. The validity of the Hospital Anxiety and Depression Scale. An updated literature review. 52, 69-77.

BRAUN, V. \& CLARKE, V. 2006. Using thematic analysis in psychology. Qualitative Research in Psychology, 3, 77-101.

BROUWER, W. B., VAN EXEL, N. J., VAN GORP, B. \& REDEKOP, W. K. 2006. The CarerQol instrument: a new instrument to measure care-related quality of life of informal caregivers for use in economic evaluations. Qual Life Res, 15, 1005-21.

BURTON, A., OGDEN, M. \& COOPER, C. 2019. Planning and enabling meaningful patient and public involvement in dementia research. Curr Opin Psychiatry, 32, 557-562.

CLARE, L., KUDLICKA, A., OYEBODE, J. R., JONES, R. W., BAYER, A., LEROI, I., KOPELMAN, M., JAMES, I. A., CULVERWELL, A. \& POOL, J. 2019. Individual goal-oriented cognitive rehabilitation to improve everyday functioning for people with early-stage dementia: A multicentre randomised controlled trial (the GREAT trial). International journal of geriatric psychiatry, 34, 709-721.

COOPER, C., MANELA, M., KATONA, C. \& LIVINGSTON, G. 2008. Screening for elder abuse in dementia in the LASER-AD study: prevalence, correlates and validation of instruments. Int J Geriatr Psychiatry, 23, 283-8.

COOPER, C., MAXMIN, K., SELWOOD, A., BLANCHARD, M. \& LIVINGSTON, G. 2009. The sensitivity and specificity of the Modified Conflict Tactics Scale for detecting clinically significant elder abuse. Int Psychogeriatr, 21, 774-8.

CSIPKE, E., MONIZ-COOK, E., LEUNG, P., YATES, L., BIRT, L., WALTON, H., HOGERVORST, E., MOUNTAIN, G., CHARLESWORTH, G. \& ORRELL, M. 2020. Feasibility and acceptability evaluation of the Promoting Independence in Dementia (PRIDE) intervention for living well with dementia. International Psychogeriatrics, 1-14.

CUMMINGS, J. L. 1997. The Neuropsychiatric Inventory: assessing psychopathology in dementia patients. Neurology, 48, 10S-116.

DEPARTMENT OF, H. \& SOCIAL, C. 2009. Living Well with Dementia: A National Dementia Strategy for England, London, Department of Health and Social Care.

DEPARTMENT OF HEALTH 2005. Mental Capacity Act. In: HEALTH, D. O. (ed.). London: HMSO. 
FELDMAN, H., SAUTER, A., DONALD, A., GELINAS, I., GAUTHIER, S., TORFS, K., PARYS, W. \& MEHNERT, A. 2001. The disability assessment for dementia scale: a 12-month study of functional ability in mild to moderate severity Alzheimer disease. Alzheimer Dis Assoc Disord, 15, 89-95.

GAGE, H., CHEYNEL, J., WILLIAMS, P., MITCHELL, K., STINTON, C., KATZ, J., HOLLAND, C. \& SHEEHAN, B. 2015. Service utilisation and family support of people with dementia: a cohort study in England. Int J Geriatr Psychiatry, 30, 166-77.

GRAFF, M. J., VERNOOIJ-DASSEN, M. J., THIJSSEN, M., DEKKER, J., HOEFNAGELS, W. H. \& RIKKERT, M. G. O. 2006. Community based occupational therapy for patients with dementia and their care givers: randomised controlled trial. Bmj, 333, 1196.

HERAT-GUNARATNE, R., COOPER, C., MUKADAM, N., RAPAPORT, P., LEVERTON, M., HIGGS, P., SAMUS, Q. \& BURTON, A. 2020. "In the Bengali Vocabulary, There Is No Such Word as Care Home": Caring Experiences of UK Bangladeshi and Indian Family Carers of People Living With Dementia at Home. Gerontologist, 60, 331-339.

JENNINGS, L. A., RAMIREZ, K. D., HAYS, R. D., WENGER, N. S. \& REUBEN, D. B. 2018. Personalized Goal Attainment in Dementia Care: Measuring What Persons with Dementia and Their Caregivers Want. J Am Geriatr Soc, 66, 21202127.

KALES, H. 2015. Assessment and management of behavioral and psychological symptoms of dementia. BMJ, 350.

LAVER, K., MILTE, R., DYER, S. \& CROTTY, M. 2017. A systematic review and meta-analysis comparing carer focused and dyadic multicomponent interventions for carers of people with dementia. Journal of aging and health, 29, 1308-1349.

LIVINGSTON, G., BARBER, J., RAPAPORT, P., KNAPP, M., GRIFFIN, M., KING, D., LIVINGSTON, D., MUMMERY, C., WALKER, Z., HOE, J., SAMPSON, E. L. \& COOPER, C. 2013. Clinical effectiveness of a manual based coping strategy programme (START, STrAtegies for RelaTives) in promoting the mental health of carers of family members with dementia: pragmatic randomised controlled trial. BMJ, 347, f6276.

LIVINGSTON, G., MANELA, M., O'KEEFFE, A., RAPAPORT, P., COOPER, C., KNAPP, M., KING, D., ROMEO, R., WALKER, Z., HOE, J., MUMMERY, C. \& BARBER, J. 2019. Clinical effectiveness of the START (STrAtegies for RelaTives) psychological intervention for family carers and the effects on the cost of care for people with dementia: 6-year follow-up of a randomised controlled trial. Br J Psychiatry, 1-8.

LIVINGSTON, G. B., J; KINNUNEN , K; WEBSTER, L; KYLE, S; COOPER, C; ESPIE, C; HALLAM, B; HORSLEY, R; PICKETT, J; RAPAPORT, P 2018. DREAMS START (Dementia RElAted Manual for Sleep; STrAtegies for RelaTives) for people with dementia and sleep disturbances: a single-blind feasibility and acceptability randomised controlled trial International Psychogeriatrics, In press.

LORD, K., BERESFORD-DENT, J., RAPAPORT, P., BURTON, A., LEVERTON, M., WALTERS, K., LANG, I., DOWNS, M., MANTHORPE, J., BOEX, S., JACKSON, J., OGDEN, M. \& COOPER, C. 2020. Developing the New Interventions for independence in Dementia Study (NIDUS) theoretical model for supporting people to live well with dementia at home for longer: a systematic 
review of theoretical models and Randomised Controlled Trial evidence. Soc Psychiatry Psychiatr Epidemiol, 55, 1-14.

LORD, K., LIVINGSTON, G., ROBERTSON, S. \& COOPER, C. 2016. How people with dementia and their families decide about moving to a care home and support their needs: development of a decision aid, a qualitative study. $B M C$ Geriatr, 16, 68.

MANTHORPE, J., ILIFFE, S., SAMSI, K., COLE, L., GOODMAN, C., DRENNAN, V. \& WARNER, J. 2010. Dementia, dignity and quality of life: nursing practice and its dilemmas. Int J Older People Nurs, 5, 235-44.

MOUNTAIN, G. 2017. Self-management programme for people with dementia and their spouses demonstrates some benefits, but the model has limitations. Evidence-Based Nursing, 20, 26-27.

NHS LONDON CLINICAL NETWORKS 2019. London memory services 2019 audit report. London: NHS.

NICE 2018. Dementia: assessment, management and support for people living with dementia and their carers. In: EXCELLENCE, N. I. F. H. A. C. (ed.). London.

NOELL, G. G., FM; GANSLE, K 2002. Does treatment integrity matter? A preliminary investigation of instructional implementation and mathematical performance. Journal of Behavioral Education 11, 15.

ORGETA, V., TUIJT, R., LEUNG, P., VERDAGUER, E. S., GOULD, R. L., JONES, R. \& LIVINGSTON, G. 2019. Behavioral Activation for Promoting Well-Being in Mild Dementia: Feasibility and Outcomes of a Pilot Randomized Controlled Trial. Journal of Alzheimer's Disease, 72, 563-574.

PRINCE, M., KNAPP, M., GUERCHET, M., MCCRONE, P., PRINA, M., COMASHERRERA, A., WITTENBERG, R., ADELAJA, B., HU, B., KING, D., REHILL, A. \& SALIMKUMAR, D. 2014. Dementia UK: update. In: SOCIETY, A. S. (ed.). London: Alzheimer's Society.

RAPAPORT, P., BURTON, A., LEVERTON, M., HERAT-GUNARATNE, R., BERESFORD-DENT, J., LORD, K., DOWNS, M., BOEX, S., HORSLEY, R., GIEBEL, C. \& COOPER, C. 2020. "I just keep thinking that I don't want to rely on people." a qualitative study of how people living with dementia achieve and maintain independence at home: stakeholder perspectives. BMC Geriatr, 20, 5.

ROCKWOOD, K., GRAHAM, J. E. \& FAY, S. 2002a. Goal setting and attainment in Alzheimer's disease patients treated with donepezil. J Neurol Neurosurg Psychiatry, 73, 500-7.

ROCKWOOD, K., GRAHAM, J. E., FAY, S. \& INVESTIGATORS, A. 2002b. Goal setting and attainment in Alzheimer's disease patients treated with donepezil. $J$ Neurol Neurosurg Psychiatry, 73, 500-7.

ROCKWOOD, K., HOWLETT, S., STADNYK, K., CARVER, D., POWELL, C. \& STOLEE, P. 2003. Responsiveness of goal attainment scaling in a randomized controlled trial of comprehensive geriatric assessment. J Clin Epidemiol, 56, 736-43.

SCOTT, I., COOPER, C., LEVERTON, M., BURTON, A., BERESFORD-DENT, J., ROCKWOOD, K., BUTLER, L. \& RAPAPORT, P. 2019. Effects of nonpharmacological interventions on functioning of people living with dementia at home: A systematic review of randomised controlled trials. Int J Geriatr Psychiatry, 34, 1386-1402.

SMEBYE, K. L., KIRKEVOLD, M. \& ENGEDAL, K. 2015. Ethical dilemmas concerning autonomy when persons with dementia wish to live at home: a qualitative, hermeneutic study. BMC health services research, 16, 21. 
SPRANGE, K., MOUNTAIN, G. A., SHORTLAND, K., CRAIG, C., BLACKBURN, D., BOWIE, P., HARKNESS, K. \& SPENCER, M. 2015. Journeying through Dementia, a community-based self-management intervention for people aged 65 years and over: a feasibility study to inform a future trial. Pilot and feasibility studies, 1, 1-14.

WOODS, B. 1999. Promoting well-being and independence for people with dementia. Int J Geriatr Psychiatry, 14, 97-105; discussion 105-9.

WOODS, B., AGUIRRE, E., SPECTOR, A. E. \& ORRELL, M. 2012. Cognitive stimulation to improve cognitive functioning in people with dementia. Cochrane Database Syst Rev, CD005562. 